\title{
QUEEN'S
UNIVERSITY
BELFAST
}

\section{Mechanism of hydrodeoxygenation (HDO) in anisole decomposition over metal loaded Brønsted acid sites: Density Functional Theory} (DFT) study

Zhang, J., Fidalgo, B., Shen, D., Zhang, X., \& Gu, S. (2018). Mechanism of hydrodeoxygenation (HDO) in anisole decomposition over metal loaded Brønsted acid sites: Density Functional Theory (DFT) study. Molecular Catalysis, 454, 30-37. https://doi.org/10.1016/j.mcat.2018.05.015

Published in:

Molecular Catalysis

Document Version:

Peer reviewed version

Queen's University Belfast - Research Portal:

Link to publication record in Queen's University Belfast Research Portal

\author{
Publisher rights \\ (C) 2018 Elsevier B.V. \\ This manuscript is distributed under a Creative Commons Attribution-NonCommercial-NoDerivs License \\ (https://creativecommons.org/licenses/by-nc-nd/4.0/), which permits distribution and reproduction for non-commercial purposes, provided the \\ author and source are cited.
}

\section{General rights}

Copyright for the publications made accessible via the Queen's University Belfast Research Portal is retained by the author(s) and / or other copyright owners and it is a condition of accessing these publications that users recognise and abide by the legal requirements associated with these rights.

\section{Take down policy}

The Research Portal is Queen's institutional repository that provides access to Queen's research output. Every effort has been made to ensure that content in the Research Portal does not infringe any person's rights, or applicable UK laws. If you discover content in the

Research Portal that you believe breaches copyright or violates any law, please contact openaccess@qub.ac.uk. 


\title{
Mechanism of hydrodeoxygenation (HDO) in anisole
}

2

\section{decomposition over metal loaded Brønsted acid sites:}

\section{Density Functional Theory (DFT) study}

\author{
Jiajun Zhanga, b, c, Beatriz Fidalgoc, Dekui Shen ${ }^{a, *}$, Xiaolei Zhang ${ }^{\mathrm{b}, *}$ Sai Gu ${ }^{\mathrm{d}}$ \\ * Corresponding author: D.S., e-mail address: 101011398@seu.edu.cn
}

X.Z., email address: xiaolei.zhang@qub.ac.uk

\footnotetext{
a Key Laboratory of Energy Thermal Conversion and Control of Ministry of Education, Southeast University, Nanjing, China

b School of Mechanical and Aerospace Engineering, Queen's University Belfast, Belfast, United Kingdom

${ }^{c}$ School of Water, Energy and Environment, Cranfield University, Cranfield, United Kingdom
}

${ }^{d}$ Faculty of Engineering and Physical Sciences, University of Surrey, Surrey, United Kingdom

\section{Abstract:}

In this work, the mechanism and intrinsic reaction energy barriers of hydrodeoxygenation (HDO) of anisole, as key stage of the catalytic decomposition over metal-loaded acid support catalysts (bi-functional catalysts), were investigated by Density Functional Theory (DFT). Common transition metals were compared in terms of their adsorption energy when adsorbing anisole molecule for the selection of loading metals. The roles of metal and acid sites in the HDO of phenolic compounds (Phs) over 
bi-functional catalyst were investigated ${ }^{1}$, and a novel HDO mechanism was proposed by combining Fukui index and bond orders of phenol molecule analyses. HDO reactions of Phs over sole acid sites and the bi-functional catalysts were modelled. The modelling results revealed that, for anisole adsorption, $\mathrm{Co}, \mathrm{Mo}, \mathrm{Ni}$ and $\mathrm{Cu}$ showed higher adsorption energy than other transition metals. Molecule analysis results showed that HDO over bi-functional catalysts was dominated by the protonation of the hydroxyl group on Phs. Reaction modelling exhibited that active metals had significant effects in lowering energy barriers of the reactions for all the Phs; the metal active sites facilitated the protonation by developing strong interaction with the adsorbed reactant, and they also aid the hydrogen molecule dissociation. Ni and Mo showed the best catalytic effect on the HDO for most Phs. The effect of side chain methyl substitutes on the HDO reactions for various Phs intermediates during anisole decomposition was also investigated by reaction modelling. Modelling results in this study were found in good agreement with experimental data.

Key words: anisole; catalytic decomposition; hydrodeoxygenation; DFT modelling; bi-

37 functional catalysts

\section{Introduction}

Increasing concern about climate change and unsustainable fossil fuel resources are attracting more and more attention to renewable clean energy [1]. Biomass is regarded as an ideal carbon resource for the production biofuels without hazardous effects to the environment [2]. Lignin is one of the three main components in lignocellulosic biomass (constituting 15-35 wt.\% of dry biomass) and the most abundant aromatic-rich bioresource [3]. Fast pyrolysis is accepted as a feasible and viable route to convert lignin into value added aromatic hydrocarbons (AHs) in fuel application [4-6]. However,

\footnotetext{
${ }^{1}$ Abbreviations: Phs, phenolic compounds; AHs, aromatic hydrocarbons; Brøn, Brønsted acid sites
} 
the primary lignin derived bio-oil cannot be directly used in fuel applications because of

47 its inadequate properties, including acidity, low calorific value, and low stability, which are a consequence of its high oxygen content in composition. Methoxyl group is an oxygen containing functional group which abundantly exists in the components present in the primary bio-oil obtained from the fast pyrolysis of lignin, such as anisole, guaiacol, syringol and their derivatives [7]. Deoxygenation reaction was identified as the key stage of the thermal decomposition of methoxyl group, leading to the prominent production of mono AHs, such as benzene, toluene and xylene (BTX). Understanding the deoxygenation during the decomposition of methoxyl group is therefore important to properly tailor the catalytic reforming process towards the desired lignin-derived AHs. Anisole (or methoxybenzene) is a prototype model compound to investigate the reactivity of methoxyl-based lignin-derived compounds [8]. The decomposition of anisole proceeds by a first stage of transmethylation and a second stage of deoxygenation reactions. Phenolic compounds (Phs) are the main products from transmethylation and are the precursors for $\mathrm{AHs}$ resulted from the deoxygenation reactions [9]. Our previous work $[10,11]$ demonstrated that ortho- and para-cresols are the predominant phenolics produced by the transmethylation of anisole. Most investigations consider the addition of hydrogen to the reaction media to favour the occurrence of hydrogenation or hydrogenolysis along with deoxygenation, termed as hydrodeoxygenation (HDO) [12-17]. Metal-based solid catalysts are widely used in the HDO reactions to produce AHs. Transition metals have been observed to be highly active for the reaction; and various supports have been studied, including inert solids (i.e. $\mathrm{SiO}_{2}, \mathrm{Al}_{2} \mathrm{O}_{3}$, Silicalite) and acid zeolites (i.e. HBeta, HZSM-5) [15,18-21]. The nature of the catalyst is considered to determine the reaction pathway [22-29].

70 Two main parallel pathways have been reported for the HDO of Phs in the decomposition of anisole, leading to different products: (1) direct HDO giving rise to the 
72 formation of $\mathrm{AHs}$ and water; and (2) hydrogenation of the phenolic ring followed by 73 deoxygenation to form cyclohexane and its derivatives, as well as water [23]. HDO over 74 metal-supported inert solid catalysts has been proved to more likely undergo ring 75 saturation and produce cyclohexanols before deoxygenation [15-17,20,23,30,31]. The 76 addition of acid supports has been argued to effectively inhibit ring saturation during 77 the HDO [15,31]. This hypothesis has been confirmed by the experimental investigation 78 with ${ }^{13} \mathrm{C}$ labelled anisole decomposition over sole acid catalyst [32]. It was observed 79 that the benzene ring remained intact throughout HDO reactions.

Even though metal loaded acid catalysts show good performance in AHs production, the mechanism for HDO over the bi-functional (metal sites and acid sites) catalysts is still not clear. Specifically, detailed interactions between reactants and catalyst surface, and the role of both metal and acid catalytic sites on the HDO mechanism have not been reported in the literature. The aim of this work is to establish by means of DFT modelling the mechanism of HDO (the second stage) in the catalytic decomposition of anisole over bi-functional catalysts, and to identify the effect of different metal loadings and acid sites on the reaction. HDO of phenol, xylenols, and tri-methyl Phs is investigated.

\section{Computational method}

The first-principle density functional theory plus dispersion (DFT-D) calculations were

91 implemented in the $\mathrm{DMol}^{3}$ module available in Materials Studio 2016 from BIOVIA $[33,34]$. The double numerical plus polarization (DNP) basis set was used to calculate the valence orbital of all the atoms, including a polarization p-function on all hydrogen atoms. The numerical basis sets in $\mathrm{Dmol}^{3}$ minimize or even eliminate basis set superposition error (BSSE), in contrast to Gaussian basis sets, in which BSSE can be a serious problem $[35,36]$. Calculations used the generalized gradient corrected approximation (GGA) [37] treated by the Perdew-Burke-Ernzerhof (PBE) exchange- 
correlation potential with long-range dispersion correction via Grimme's scheme [38]. The self-consistent field (SCF) procedure was used with a convergence threshold of $10^{-6}$ au on the energy and electron density. Geometry optimizations were performed with a convergence threshold of $0.002 \mathrm{Ha} / \AA$ on the gradient, $0.005 \AA$ on displacements, and $10^{-5} \mathrm{Ha}$ on the energy. The real-space global cut-off radius was set to $5 \AA$. In this study, no symmetry constraints were used for any cluster models. The transition state was completely determined by the LST/QST method, and confirmed by the unique imaginary frequency as shown in $\mathrm{S} 1$ of the Supplementary Material and the intrinsic reaction coordinate (IRC) calculation. Free energy of each transition state at $600^{\circ} \mathrm{C}^{2}$ was determined as shown in S2 of the Supplementary Material. Mulliken charges were assigned to each bond to address the bond order, and Hirshfeld charges were assigned to each atom for the function selected as the Fukui field [39]. All the adsorbent models were based on single metal loaded Brønsted acid sites (see Figure S3). The adsorption energy $E_{a d}$ was determined by Eq.1, where $E_{c a t a l y s t, ~} E_{a d s o r b a t e}$ and Eadsorbate/catalyst are the total energies of clean metal loaded catalyst, free adsorbate molecule and catalysts with molecule respectively. The initial configuration of the $8 T$ model to simulate the Brøn was adopted from the MFI structure $[40,41]$. One metal atom was loaded on the Brøn to simulate ideally dispersed metal site in bi-functional catalyst. All the models of bi-functional catalysts, adsorbate, and reactants were optimized to find their most stable structures before adsorption and reaction modelling. The energy barriers of reactions $\mathrm{E}_{\text {barrier }}$ were determined by the difference between the transition state and reactant energies, as shown in Eq.2, where $E_{\text {transition state }}$ and $E_{\text {reactant }}$ are the total energies of the transition state and reactant of a reaction. All the energies were calculated at $\mathrm{OK}$ in this DFT investigation.

$$
E_{a d}=E_{\text {catalyst }}+E_{\text {adsorbate }}-E_{\text {adsorbate/catalyst }}
$$

\footnotetext{
${ }^{2}$ Hydrodeoxygenation of anisole derived phenolic compounds was found in experimental investigation to be dominating reaction around $600^{\circ} \mathrm{C}$ over pure HZSM-5 catalyst [10].
} 


\section{3. Results and discussion}

\section{3.1. Anisole adsorption on the surfaces of transition metals}

126 Adsorption happens as the first step of catalytic reactions and consists of the link

127 between the reactants and the catalyst active sites [42-44]. It has been reported that

128 adsorption plays an important role in determining the selectivity to desired products, i.e.

129 BTX, during the HDO in anisole decomposition [17]. The adsorption energy of the

130 reactant onto metal loadings was evaluated to predict the performance of metals as

131 active sites, and aid the selection of the preferred metal catalysts. Thus, cluster models

132 with eleven transition metals, i.e. $\mathrm{Mn}, \mathrm{Fe}, \mathrm{Co}, \mathrm{Ni}, \mathrm{Cu}, \mathrm{Zn}, \mathrm{Mo}, \mathrm{Ru}, \mathrm{Rh}, \mathrm{Pd}$, and $\mathrm{Pt}$, were

133 built and compared in terms of their performance in the adsorption of molecular anisole,

134 used as model of molecules existing in real HDO reactions. Fig. 1 shows the calculated

135 values of the adsorption energy of anisole onto the metal/Brøn.

136 In the perspective of thermodynamic, high adsorption energy implies strong binding 137 between the anisole molecule and the metal surfaces. It can be seen that $\mathrm{Co}, \mathrm{Mo}, \mathrm{Ni}$ 138 and $\mathrm{Cu}$ exhibited the highest adsorption energy values. On the contrary, Mn, Fe and $\mathrm{Zn}$ 139 showed the lowest adsorption energy, corresponding to weak binding between the 140 catalytic site and the adsorbates. Based on these results, $\mathrm{Ni}, \mathrm{Mo}, \mathrm{Cu}$ and Co were 141 further considered as metal sites used of the bi-functional catalysts for the modelling 142 investigation of the HDO reaction. 


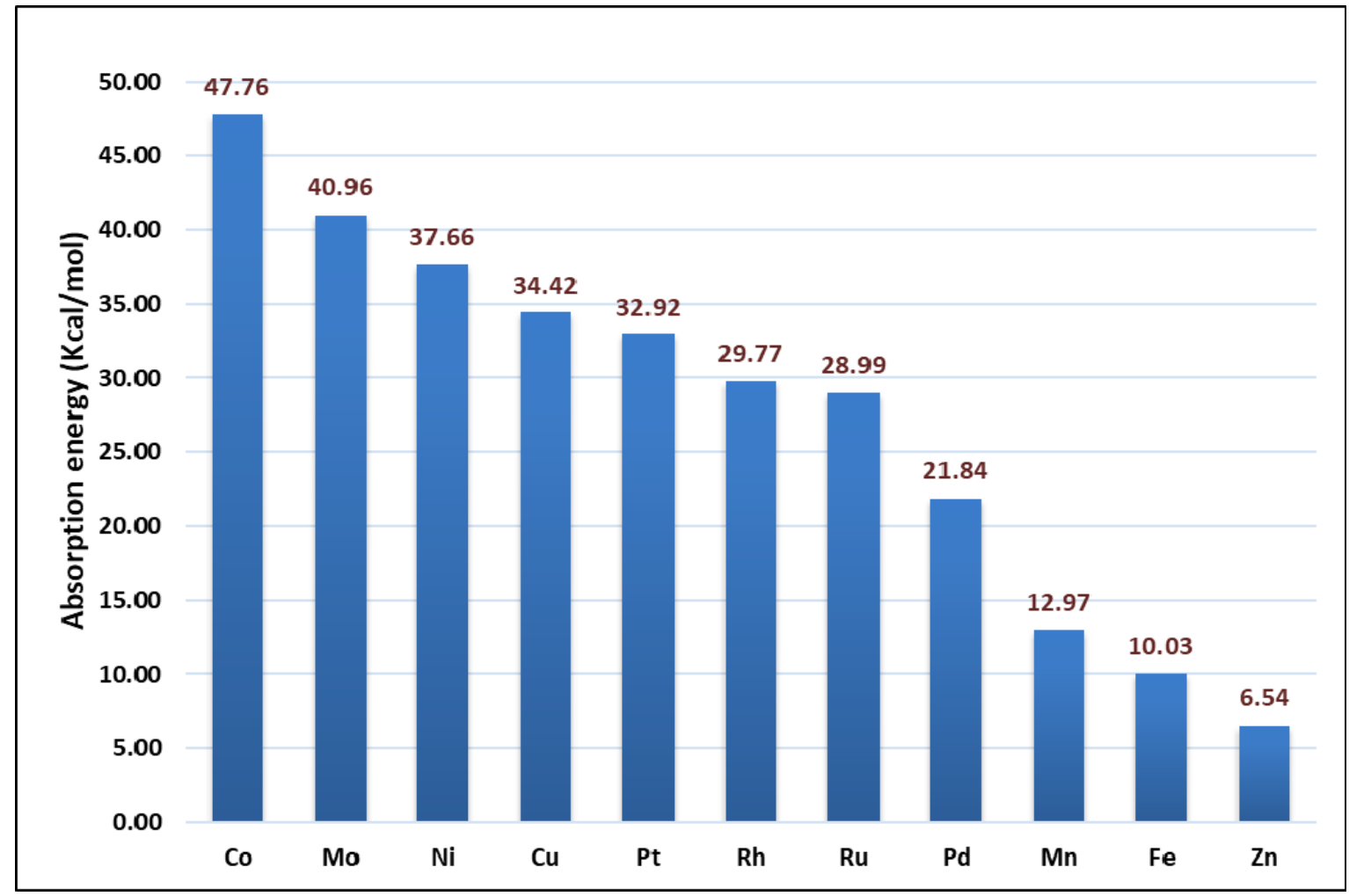

Fig. 1 Adsorption energy of anisole onto metal/Brøn

\subsection{Mechanism of HDO of Phs in catalytic anisole decomposition}

146 The Phs produced from transmethylation stage in the anisole catalytic decomposition

147 are the main reactants for the catalytic deoxygenation stage [10]. Although there is no agreement on the mechanism for $\operatorname{HDO}[8,18,31,32,45,46]$, it is accepted that the occurrence of a straightforward hydrogenolysis reaction in the HDO of Phs is unlikely because the $\mathrm{C}_{\mathrm{sp}}{ }^{2}-\mathrm{O}$ bond strength is reinforced by the $\pi-p$ conjugation compared to aliphatic hydroxyl [15]. Besides, many studies confirmed that the Brøn play an

152 important role in enhancing the HDO reaction [15,32], implying that the HDO reactions 153 of Phs are likely to commence through the electrophilic attack by protons (protonation).

154 Therefore, using a phenol molecule as representative of Phs compounds, a Fukui analysis was performed to evaluate the reactivity of each atom to an electrophilic attack. As shown in Fig. 2, the oxygen, para-carbon (C2), ortho-carbon $(\mathrm{C} 4, \mathrm{C} 6)$, and the carbon linked to oxygen (C5) were identified as the most vulnerable sites to 
158 electrophilic attack on the phenol molecule. These results are in line with the 159 electrophilic substitution priority observed in experiments [10]. Two possible 160 electrophilic attack mechanisms for the HDO reaction of Phs were proposed based on 161 the protonation of carbon or oxygen atoms respectively. The "carbon protonation 162 mechanism" considers that the reaction is initiated through an electrophilic attack by a 163 proton to one of the ring carbons (Fig. 3), while the "hydroxyl protonation mechanism" 164 considers the electrophilic attack to the hydroxyl group (Fig. 4).

\begin{tabular}{lll} 
Atom & Fukui (-) index \\
$\mathrm{O} 7$ & 0.152 \\
$\mathrm{C} 2$ & 0.136 \\
$\mathrm{C} 4$ & 0.089 \\
$\mathrm{C} 5$ & 0.089 \\
$\mathrm{C} 6$ & 0.083 \\
$\mathrm{C} 1$ & 0.073 \\
$\mathrm{C} 3$ & 0.068 \\
& $\mathrm{H} 9$ & 0.061 \\
$\mathrm{H} 13$ & 0.055 \\
$\mathrm{H} 11$ & 0.050 \\
$\mathrm{H} 8$ & 0.049 \\
$\mathrm{H} 10$ & 0.048 \\
$\mathrm{H} 12$ & 0.048 \\
\hline
\end{tabular}

Fig. 2 Fukui indices for electrophilic attack on phenol molecule (Fukui (-)). Atoms are coloured as follows: carbon atom (grey), hydrogen atom (white) and oxygen atom (red)

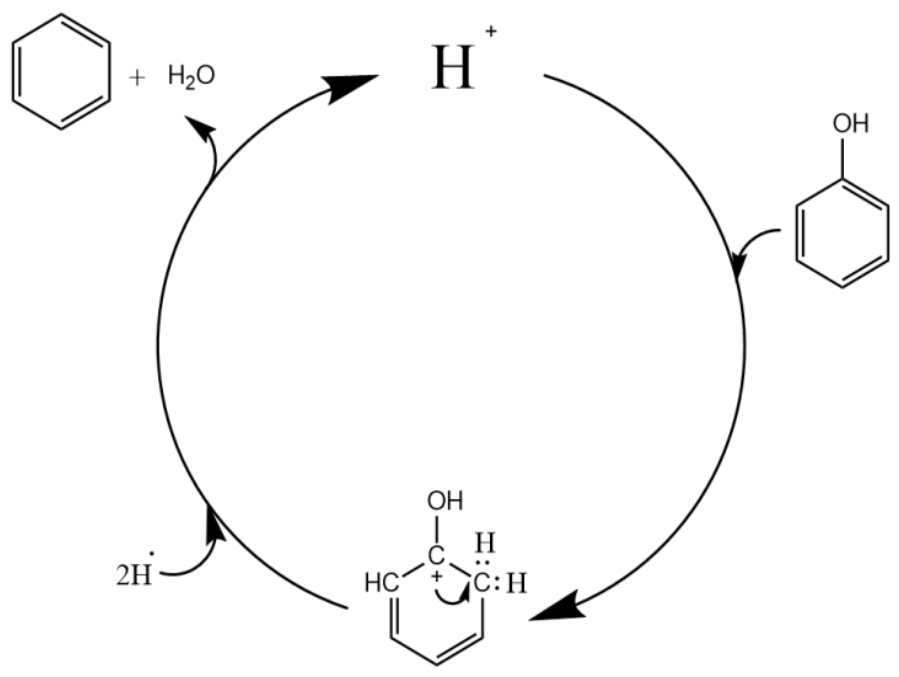




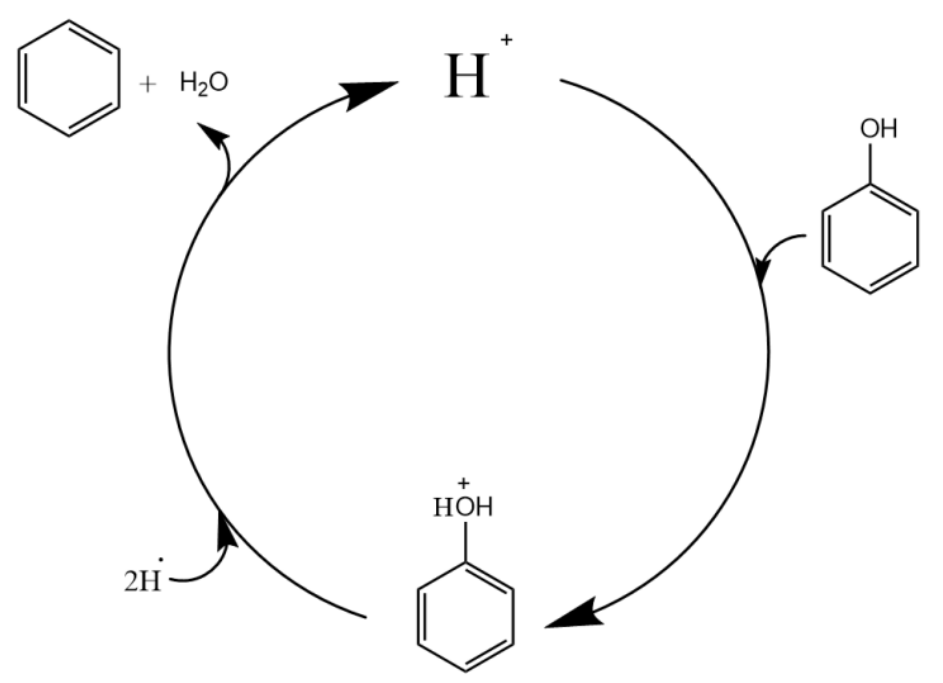

Fig. 4 Hydroxyl protonation mechanism for HDO of phenol

171 Since the oxygen atom exhibits the highest Fukui index (i.e. 0.152), it was inferred that 172 the HDO reaction is more likely to be initiated by the electrophilic attack to the oxygen 173 by a proton. To confirm this hypothesis, the possible cations formed under carbon and hydroxyl protonation of the carbon and oxygen atoms that exhibit high Fukui index were compared, and the bond orders of $\mathrm{C}_{\mathrm{sp}^{2}}{ }^{2} \mathrm{O}$ were assessed accordingly (Fig. 5). Fig. 5 shows that the proton attack to different positions gave rise to significant change of 177 the $\mathrm{C}_{\mathrm{SP}^{2}}{ }^{2} \mathrm{O}$ bond order. The bond orders of $\mathrm{C}_{\mathrm{sp}}{ }^{2}-\mathrm{O}$ were 0.781 and 0.668 when the 178 proton attacked C6 (Fig. 5(a)) and C5 (Fig. 5(b)), respectively. The electrophilic attack to the $\mathrm{C} 2$ atom resulted in the $\mathrm{C}_{\mathrm{sp}}{ }^{2}-\mathrm{O}$ bond order of 0.783 (Fig. $5(\mathrm{~d})$ ), and it was 0.397 when both oxygen and $\mathrm{C} 4$ are under electrophilic attack (Fig. 5(e)). The lowest $\mathrm{C}_{\mathrm{sp}}{ }^{2}-\mathrm{O}$ bond order of 0.332 was attributed to the oxygen atom under electrophilic attack (Fig. 5(c)). This result reveals that the $\mathrm{C}_{\mathrm{sp}}{ }^{2}-\mathrm{O}$ bond strength is significantly weakened when

183 the proton attacks the phenol molecule at oxygen atom, and confirms the hypothesis of 184 the HDO reaction being most likely to commence following the hydroxyl protonation in 185 the presence of the Brøn. 
186

187

188

189

190

191

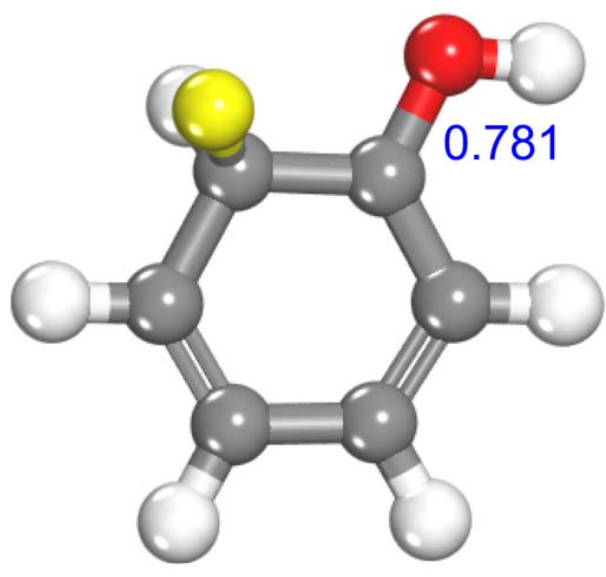

(a)

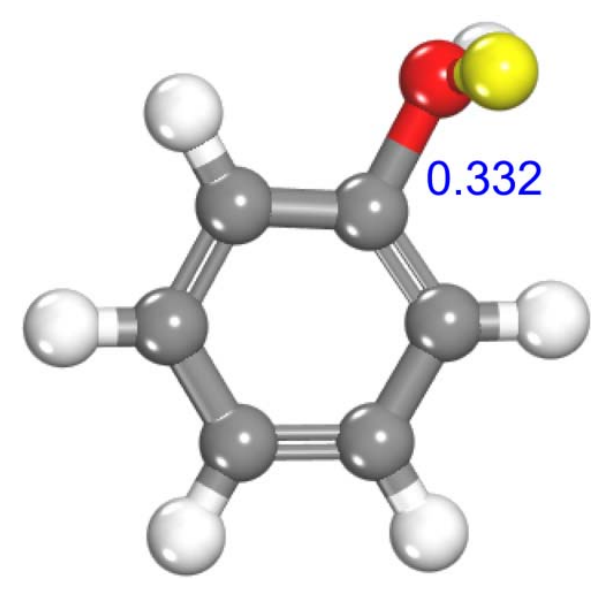

(c)

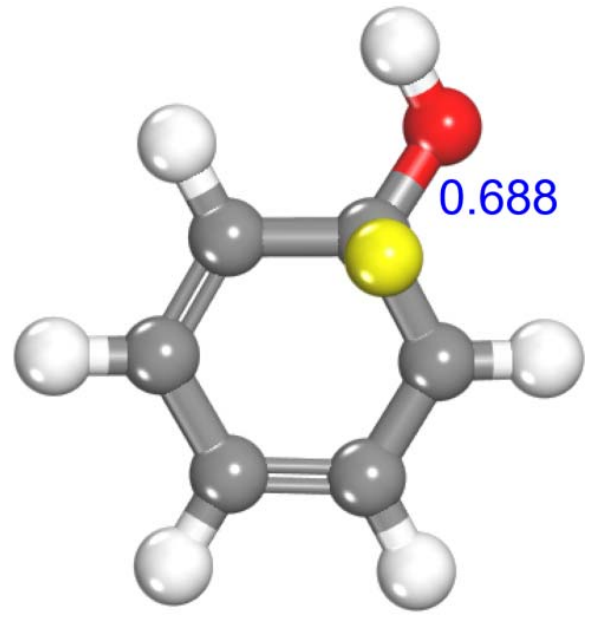

(b)

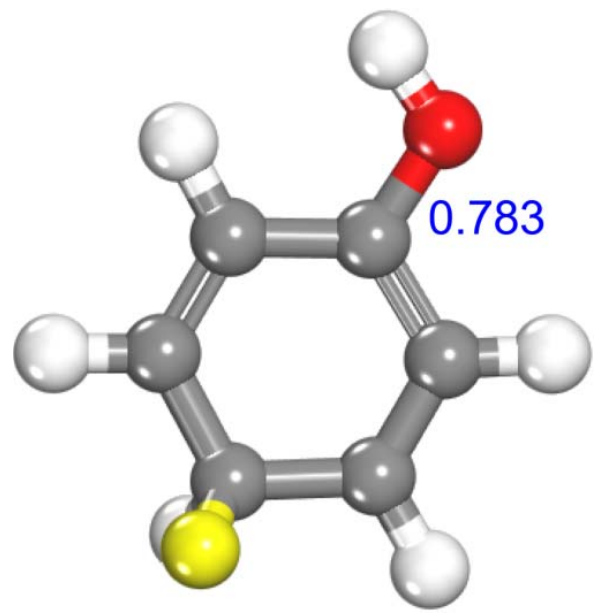

(d)

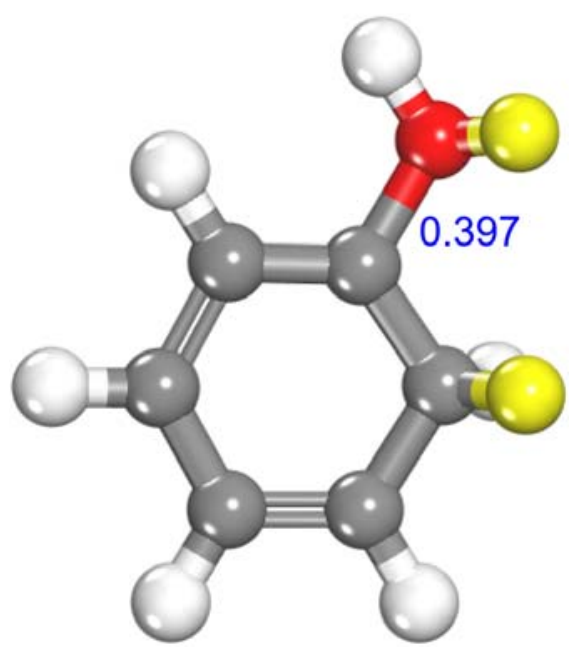

(e) 

oxygen and ortho-carbon (C4). Atoms are coloured as follows: carbon atom (grey), hydrogen atom (light grey), oxygen atom (red), and proton (yellow).

Based on this analysis, it is considered that the most likely mechanism of the HDO reaction of $\mathrm{Phs}$ in the anisole catalytic decomposition is the "hydroxyl protonation mechanism". As depicted in Fig. 4, this reaction pathway consists of the electrophilic attack reaction, followed by a reduction reaction and a substitution reaction. The proton from Brøn attacks the oxygen atom and enables the formation of an aromatic cation. The cation is then reduced by one of the hydrogen atoms from hydrogen molecule and substituted by another hydrogen atom to produce a molecule of water and an $\mathrm{AH}$ compound (represented by a benzene molecule in Fig. 4). Meanwhile, the oxidised hydrogen atom becomes a new proton, and the acid site is recovered. Overall, there are two hydrogen atoms engaging in the reaction.

\subsection{Modelling of the HDO reaction of Phs in catalytic anisole} decomposition over bi-functional catalyst

The HDO reactions of phenol, cresols, xylenols and trimethyl phenols over metalsupported Brøn were modelled as second stage of the catalytic decomposition of anisole. $\mathrm{Ni}$, Co, Mo and $\mathrm{Cu}$ were evaluated as active metal sites loaded on the Brøn,

211 and phenol, o-cresol, p-cresol, 2,4-xylenol, 2,6-xylenol, 3,5-xylenol, 2,4,6212 trimethylphenol, 2,3,6- trimethylphenol and 3,4,5-trimethylphenol were modelled as reactants. These phenolic compounds are intermediates of the process obtained from

214 the transmethylation of anisole [10,47-49]. Catalytic HDO reactions over sole Brøn (no 215 metal loaded) were also modelled for comparison. Both Brøn and metal/Brøn catalytic 216 HDO models were built by locating equidistantly the reactant molecule (within $3 \AA$ ) over 217 the acid site before the geometry optimization to minimize any possible position-related 
errors. In both cases, the catalytic HDO reaction was modelled based on the hydroxyl

219 protonation mechanism shown in Fig. 4. The HDO reaction of phenol over Brøn and 220 over Ni/Brøn are shown in Fig. 6 (a) and (b), respectively, as examples of the catalytic 221 HDO reactions of Phs. The transition state was the one with the highest energy 222 throughout both reactions (over sole Brøn and Ni/Brøn). It worth noting that in the reaction over $\mathrm{Ni} / \mathrm{Br} ø \mathrm{n}$; a ligand centred on the metal that connected the reactant molecule and the support was formed, and the hydrogen molecule was also bound to the metal atom and dissociated into two atoms. Examples for the reactions of Phs over other metal/Brøn catalysts are shown in S4 of the Supplementary Material.

Transition state
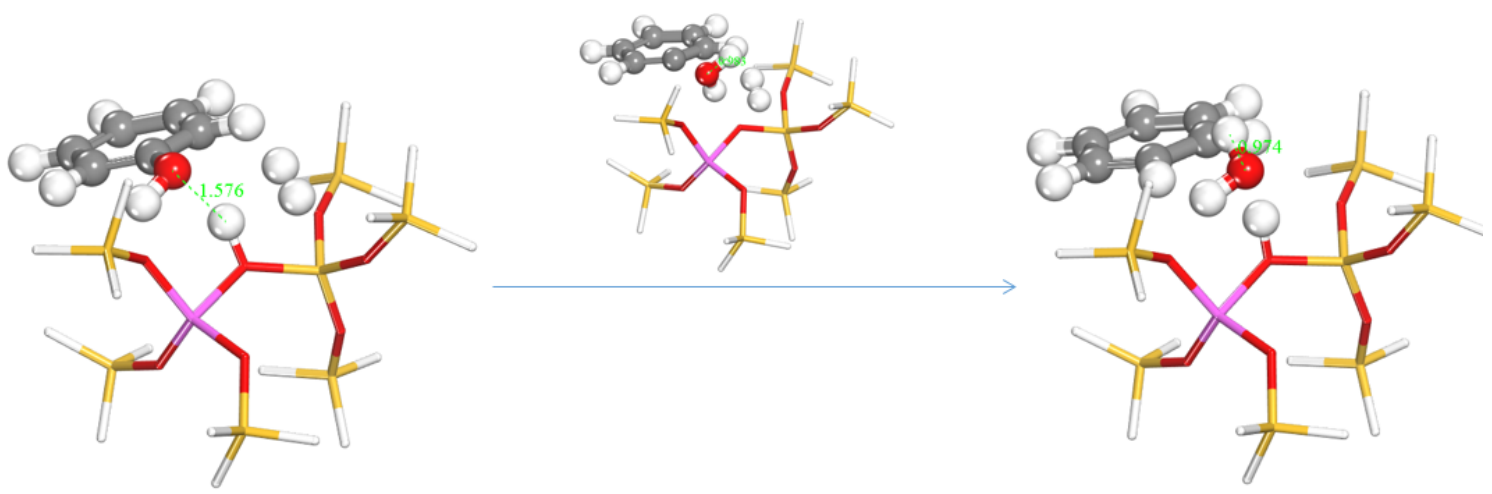

(a)

Transition state

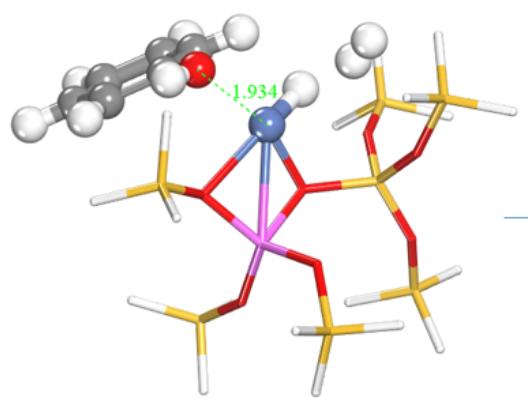

Phenol over Ni/Brøn
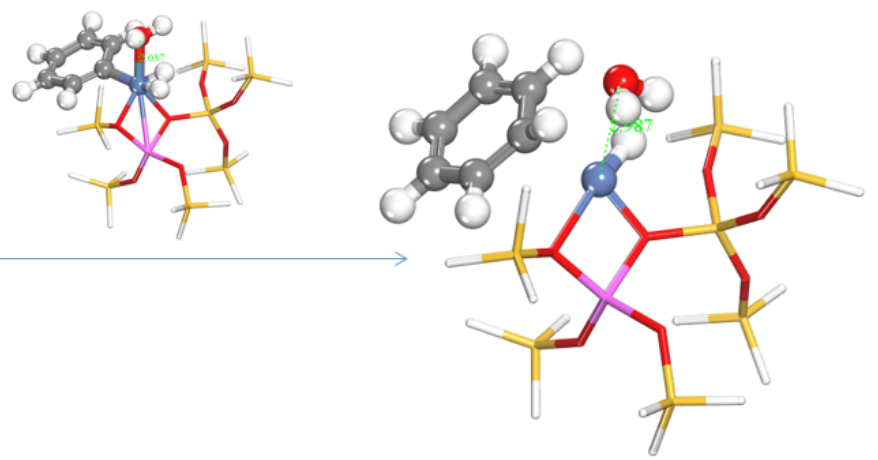

Benzene \& water over $\mathrm{Ni} / \mathrm{Br} \varnothing \mathrm{n}$ 
231 Fig. 6. Modelling of the HDO reactions of phenol molecule over (a) sole Brøn catalyst; 232 and, (b) Ni/Brøn catalyst. Atoms are coloured as follows: carbon atom (grey), hydrogen 233 atom (light grey), oxygen atom (red), silica atom (yellow), aluminium atom (pink) and nickel atom (blue).

235 The intrinsic energy barriers for the HDO reactions of the Phs over respective Brøn and 236 metal/Brøn catalysts were calculated and are summarized in Table1. In the case of 237 non-metal Brøn catalytic reactions, the energy barriers of HDO changed by as much as $25.4 \mathrm{kcal} / \mathrm{mol}$ depending on the reactant molecules. This is related to the fact that the number and position of methyl groups in the reactant molecule affect the inner electron distribution of the aromatic rings [50]. Thus, the HDO of phenol presented an energy barrier of $93.4 \mathrm{kcal} / \mathrm{mol}$, while the HDO of o-cresol and p-cresol exhibited lower energy

242 barriers of $74.2 \mathrm{kcal} / \mathrm{mol}$ and $89.0 \mathrm{kcal} / \mathrm{mol}$ respectively. This result implies the positive 243 effect of the presence of a single methyl group in the Phs molecule on the Csp²-O bond 244 activation, especially when the methyl group was at 2-ortho position (o-cresol). The evaluation of HDO of multi-methyl Phs gave rise to a broad range of energy barrier values. An energy barrier of $77.1 \mathrm{kcal} / \mathrm{mol}$ was obtained in the case of the reaction of 247 2,4-xylenol, which confirms the positive effect of the presence of methyl groups on 248 ortho and para positions on the HDO reaction. In the case of HDO of 2,6-xylenol, 2,3,6249 trimethyl phenol and 2,4,6-trimethyl phenol, energy values higher than that observed 250 for the HDO of phenol were observed. This result implies that the presence of methyl 251 groups on both ortho positions decreases the molecule reactivity in the HDO reactions because of the steric hindrance effect caused by multi-methyl group close to the hydroxyl [51]. 
254 Table1. Energy barriers of the HDO reactions for various phenolic compounds over

255 Brøn and metal/Brøn catalysts as the second stage of the catalytic decomposition of 256 anisole. Metal active sites: $\mathrm{Ni}, \mathrm{Co}, \mathrm{Mo}$, and $\mathrm{Cu}$.

\begin{tabular}{|c|c|c|c|c|c|c|c|c|c|}
\hline \multirow{2}{*}{$\begin{array}{l}\text { Phs } \\
\text { (reactants) }\end{array}$} & \multicolumn{9}{|c|}{ Energy barrier (kcal/mol) } \\
\hline & Brøn & $\begin{array}{c}\mathrm{Ni} / \mathrm{Br} \varnothing \\
\mathrm{n}\end{array}$ & $\begin{array}{c}\text { Decline by } \\
(\%)\end{array}$ & $\begin{array}{c}\mathrm{Co} / \mathrm{Br} \varnothing \\
n\end{array}$ & $\begin{array}{c}\text { Decline by } \\
(\%)\end{array}$ & $\begin{array}{c}\mathrm{Mo} / \mathrm{Br} \\
\varnothing \mathrm{n}\end{array}$ & $\begin{array}{c}\text { Decline by } \\
(\%)\end{array}$ & $\begin{array}{c}\mathrm{Cu} / \mathrm{Br} \varnothing \\
\mathrm{n}\end{array}$ & $\begin{array}{c}\text { Decline by } \\
(\%)\end{array}$ \\
\hline phenol & 93.4 & 18.9 & 79.8 & 32.7 & 65.0 & 14.3 & 84.6 & 13.5 & 85.6 \\
\hline o-cresol & 74.2 & 38.0 & 48.7 & 18.1 & 75.5 & 30.0 & 59.6 & 23.9 & 67.9 \\
\hline p-cresol & 89.0 & 27.9 & 68.7 & 31.2 & 64.9 & 37.1 & 58.3 & 54.7 & 38.6 \\
\hline 2,4-xylenol & 77.1 & 13.3 & 82.8 & 15.7 & 79.6 & 12.5 & 83.8 & 56.0 & 27.4 \\
\hline 2,6-xylenol & 99.6 & 15.1 & 84.8 & 55.3 & 44.5 & 16.0 & 83.9 & 79.9 & 19.8 \\
\hline 3,5-xylenol & 81.8 & 58.7 & 28.2 & 26.1 & 68.1 & 14.0 & 82.9 & 26.1 & 68.1 \\
\hline 2,4,6-tri-ph & 95.7 & 43.8 & 54.2 & 39.3 & 59.0 & 26.5 & 72.3 & 30.5 & 68.1 \\
\hline 2,3,6-tri-ph & 97.0 & 13.5 & 86.1 & 34.4 & 64.5 & 33.9 & 65.1 & 63.8 & 34.3 \\
\hline 3,4,5-tri-ph & 86.5 & 20.0 & 76.9 & 10.5 & 87.8 & 26.9 & 68.9 & 70.3 & 18.7 \\
\hline
\end{tabular}

257 The results obtained from the HDO reactions over metal/Brøn catalyst showed notable

258 decreases in the energy barrier values for the reactions of all the phenolic compounds

259 and confirmed that the presence of these four metals that lead to larger binding energy 260 may significantly facilitate the HDO reaction [17,52]. In the case with $\mathrm{Ni} / \mathrm{Br} ø n$ catalyst,

261 all the energy barriers were below $60 \mathrm{kcal} / \mathrm{mol}$, and the energy barriers for HDO of

262 phenol, 2,4-xylenol, 2,6-xylenol, 2,3,6-trimethylphenol and 3,4,5-trimethylphenol 263 decreased more significantly to be lower than $20 \mathrm{kcal} / \mathrm{mol}$. This result points that the 264 presence of the metal site compensated the steric hindrance effect observed in HDO of 265 phenolics with methyls on both ortho positions over sole Brøn catalyst. In the case with $266 \mathrm{Co} / \mathrm{Brøn}$ catalyst, the highest energy barrier was $55.3 \mathrm{kcal} / \mathrm{mol}$ for the HDO of 2,6xylenol, and the energy barriers for o-cresol, 2,4-xylenol and 3,4,5-trimethylphenol 268 were lower than $20 \mathrm{kcal} / \mathrm{mol}$. Regarding Mo/Brøn catalyst, all energy barrier values 269 were found to be lower than $40 \mathrm{kcal} / \mathrm{mol}$, and those for phenol, 2,4-xylenol, 2,6-xylenol 270 and 3,5-xylenol were lower than $20 \mathrm{kcal} / \mathrm{mol}$. Cu/Brøn catalyst also showed a positive 271 effect in decreasing the energy barrier values. For example, in the case of the HDO of 272 phenol, the energy barrier was $13.5 \mathrm{kcal} / \mathrm{mol}$. Nevertheless, it is worth noting that the 
273 effect of $\mathrm{Cu}$ on the decrease of the HDO energy barriers was much more moderate

274 than that from $\mathrm{Ni}, \mathrm{Co}$, and Mo. This may be related with the lower adsorption energy

275 (i.e. less strong binding between reactant and metal surface) that Cu presents.

276 Reductions in the energy barrier values due to the presence of the metals larger than $27770 \%$ are highlighted in red in Table1. It is observed that Ni/Brøn and Mo/Brøn achieved 278 the highest number and average reduction in the HDO reaction energy barrier values 279 among the four tested metals, indicating the most effective metals for the HDO reaction 280 of Phs are $\mathrm{Ni}$ and Mo. This can be due to the intermediate adsorption energy shown by $281 \mathrm{Ni}$ and Mo among the four metals; they adsorb the reactants strongly enough to hold 282 and activate them compared to $\mathrm{Cu}$, but moderately compared to $\mathrm{Co}$, which allows the 283 desorption of the products [53]. It is also observed that Mo/Brøn catalyst is more effective on lowering the energy barrier for the most abundant intermediate Phs compounds in the anisole decomposition system, such as phenol and xylenols. Ni/Brøn exhibits excellent effect on the HDO reactions for phenol, xylenols and trimethylphenols. Large drops in the energy barrier values confirm that the presence of metal active sites may promote the catalytic effect of the Brøn present in the solid support by enhancing the reactivity of Phs for protonation (change the inner electron density of the adsorbed molecules) and by dissociating dihydrogen molecules [54-56]. Furthermore, as explained above, both $\mathrm{Ni}$ and $\mathrm{Mo}$ are found to compensate the steric hindrance and promote the HDO of Phs with methyl groups on both ortho positions.

\subsection{Comparison of modelling results with experimental data}

294 Experiments of anisole decomposition were carried out in previous work of our group, and the BTX yield and selectivity over pure HZSM-5 zeolite $(\mathrm{Si} / \mathrm{Al}=25, \mathrm{HZ}(25))$ and single metal (Co, Mo, Ni and $\mathrm{Cu}$ ) loaded HZSM-5 catalysts are shown in Table 2 [9]. As compared with the modelling results based on Brønsted acid sites in this study. 
299 Table 2. BTX yield and selectivity of anisole deoxygenation over the metal loaded $300 \mathrm{HZSM}-5$ zeolites at $500^{\circ} \mathrm{C}[9]$

\begin{tabular}{llllll}
\hline Catalyst & $\mathrm{HZ}(25)$ & $1 \% \mathrm{Ni} / \mathrm{HZ}(25)$ & $1 \% \mathrm{Co} / \mathrm{HZ}(25)$ & $1 \% \mathrm{Mo} / \mathrm{HZ}(25)$ & $1 \% \mathrm{Cu} / \mathrm{HZ}(25)$ \\
BTX yield (wt.\% reactant) & 23.6 & 25.6 & 25.9 & 30.0 & 28.3 \\
BTX selectivity (wt.\% liquid fraction) & 57.1 & 81.9 & 68.8 & 77.4 & 69.3 \\
\hline
\end{tabular}

301 Experimental investigation revealed all the four metals are effective in promoting the 302 deoxygenation reaction, leading to both higher yield and selectivity of BTX in anisole

303 decomposition. This could be sufficiently explained in microscale by the contribution of 304 metal loading on Brøn in promoting HDO reactions by dramatically decreasing the 305 energy barriers.

306 Based on the experiments data, $\mathrm{Ni}$ and Mo exhibited the best effects in deoxygenation 307 of anisole decomposition among the four metals; Ni loading led to the highest BTX 308 selectivity by converting more Phs to monocyclic AHs, while Mo loading presented the 309 best catalytic activity towards the highest overall AHs yield. The outstanding 310 deoxygenation performance of $\mathrm{Ni} / \mathrm{HZ}(25)$ and $\mathrm{Mo} / \mathrm{HZ}(25)$ in anisole decomposition are 311 in good line with the superior property of Ni/Brøn and Mo/Brøn in lowering energy 312 barriers observed in this study.

\section{4. Conclusion}

314 In this work a mechanism for the HDO of phenolic compounds over bi-functional (metal 315 and acid sites) catalysts was established by means of DFT modeling results. Ni, Co, 316 Mo and Cu were selected as active metals after the modelling of anisole adsorption on 317 transition metal surfaces revealed that the four metals exhibited the highest adsorption energy values. Results confirmed that catalytic HDO of Phs, which are intermediate compounds in the catalytic decomposition of anisole, was initiated from hydroxyl protonation and that the presence of metals on the catalysts promoted both the 
reaction and the dissociation of the hydrogen molecule. Thus, the presence of active

322 metals, particularly $\mathrm{Ni}$ and $\mathrm{Mo}$, led to significant decrease in the energy barriers for the 323 HDO reactions of various Phs. Modelling of the HDO reaction over non-metal acid 324 catalyst showed that a single methyl group on the ortho-position of the phenolic compound enhanced the $\mathrm{Csp}^{2}-\mathrm{O}$ bond and promoted the reactivity. The presence of methyl groups on the two ortho-positions pointed to an inhibition of the reaction due to steric hindrance effect when using non-metal acid catalyst. However, the addition of a metal site was found to compensate this effect and promote the HDO of these phenolic compounds. The excellent activity of metal/Brøn sites were found in line with the HDO performance of corresponding catalysts in experiments.

\section{Author information}

\section{Corresponding Authors}

\section{D.S.: 101011398@seu.edu.cn}

\section{X.Z.: xiaolei.zhang@qub.ac.uk}

\section{Author Contributions}

336 All authors have given approval to the final version of the manuscript.

\section{$337 \quad$ Notes}

338 The authors declare no competing financial interest.

\section{Acknowledgement}

340 This work was supported by the National Natural Science Foundation of China (project references: 51476034 and 51628601), Natural Science Foundation of Jiangsu Province

342 (project reference: BK20161423), the FP7 Marie Curie iComFluid (project reference:

343 312261), and the Leverhulme Trust Research Grant (project reference: RPG-2017344 254). 


\section{References}

346 [1] D.A. Ruddy, J.A. Schaidle, J.R. Ferrell III, J. Wang, L. Moens, J.E. Hensley, compounds, Green Chem. 16 (2014) 454-490. doi:10.1039/C3GC41354C.

[2] M. He, Y. Sun, B. Han, Green Carbon Science: Scientific Basis for Integrating Carbon Resource Processing, Utilization, and Recycling, Angew. Chemie Int. Ed.

[3] W.-J.J. Liu, H. Jiang, H.-Q.Q. Yu, Thermochemical conversion of lignin to functional materials: a review and future directions, Green Chem. 17 (2015) 4888-4907. doi:10.1039/C5GC01054C.

[4] A.V. Bridgwater, Review of fast pyrolysis of biomass and product upgrading, Biomass and Bioenergy. 38 (2012) 68-94. doi:10.1016/j.biombioe.2011.01.048.

A.V. Bridgwater, G.V.C. Peacocke, Fast pyrolysis processes for biomass, $\begin{array}{lllll}\text { Renew. } & \text { Sustain. } & \text { Energy } & \text { Rev. } 4 \text { (2000) }\end{array}$ http://www.scopus.com/inward/record.url?eid=2-s2.00033896848\&partnerlD=40\&md5=0e406f0c2ff98f9795d0fec8732b9103.

[6] K.A. Jung, S.H. Woo, S.-R. Lim, J.M. Park, Pyrolytic production of phenolic compounds from the lignin residues of bioethanol processes, Chem. Eng. J. 259 (2015) 107-116. doi:10.1016/j.cej.2014.07.126.

D.K. Shen, S. Gu, K.H. Luo, S.R. Wang, M.X. Fang, The pyrolytic degradation of wood-derived lignin from pulping process, Bioresour. Technol. 101 (2010) 61366146. doi:10.1016/j.biortech.2010.02.078. 
fragmentation by use of model compounds, Ind. Eng. Chem. Fundam. 22 (1983) 426-430. doi:10.1021/i100012a012.

371 [9] J. Zhang, B. Fidalgo, A. Kolios, D. Shen, S. Gu, Mechanism of deoxygenation in anisole decomposition over single-metal loaded HZSM-5: Experimental study, Chem. Eng. J. 336 (2018) 211-222. doi:10.1016/j.cej.2017.11.128.

[10] J. Zhang, B. Fidalgo, D. Shen, R. Xiao, S. Gu, Mechanism of transmethylation in anisole decomposition over HZSM-5: Experimental study, J. Anal. Appl. Pyrolysis. 122 (2016) 323-331. doi:10.1016/j.jaap.2016.09.009.

J. Zhang

B. Fidalgo, A. Kolios,

D. Shen,

S. Gu, The mechanism of 378 transmethylation in anisole decomposition over Brønsted acid sites: density functional theory (DFT) study, Sustain. Energy Fuels. 1 (2017) 1788-1794. doi:10.1039/C7SE00280G.

[12] S. Jin, Z. Xiao, C. Li, X. Chen, L. Wang, J. Xing, W. Li, C. Liang, Catalytic 383 hydrodeoxygenation of anisole as lignin model compound over supported nickel catalysts, Catal. Today. 234 (2014) 125-132. doi:10.1016/j.cattod.2014.02.014.

[13] Q. Song, J. Cai, J. Zhang, W. Yu, F. Wang, J. Xu, Hydrogenation and cleavage of the $\mathrm{C}-\mathrm{O}$ bonds in the lignin model compound phenethyl phenyl ether over a nickel-based catalyst, Chinese J. Catal. 34 (2013) 651-658. doi:10.1016/S18722067(12)60535-X.

388

[14] Y. Takagi, The hydrogenation of o-, m-, and p-cresols with a rhodium catalyst, J. Catal. 8 (1967) 100-103. doi:10.1016/0021-9517(67)90289-8.

[15] X. Zhu, L.L. Lobban, R.G. Mallinson, D.E. Resasco, Bifunctional transalkylation and hydrodeoxygenation of anisole over a Pt/HBeta catalyst, J. Catal. 281 (2011) 21-29. doi:10.1016/j.jcat.2011.03.030.

[16] S.A. Khromova, A.A. Smirnov, O.A. Bulavchenko, A.A. Saraev, V. V. Kaichev, 
S.I. Reshetnikov, V.A. Yakovlev, Anisole hydrodeoxygenation over $\mathrm{Ni}-\mathrm{Cu}$ bimetallic catalysts: The effect of $\mathrm{Ni} / \mathrm{Cu}$ ratio on selectivity, Appl. Catal. A Gen. 470 (2014) 261-270. doi:10.1016/j.apcata.2013.10.046.

[17] I.T. Ghampson, G. Pecchi, J.L.G. Fierro, A. Videla, N. Escalona, Catalytic hydrodeoxygenation of anisole over Re-MoO x /TiO 2 and Re-VO x /TiO 2 catalysts, Appl. Catal. B Environ. $208 \quad$ (2017) 60-74. doi:10.1016/j.apcatb.2017.02.047.

[18] R.C. Runnebaum, T. Nimmanwudipong, D.E. Block, B.C. Gates, Catalytic conversion of compounds representative of lignin-derived bio-oils: a reaction network for guaiacol, anisole, 4-methylanisole, and cyclohexanone conversion catalysed by Pt/Y-Al2O3, Catal. Sci. Technol. 2 (2012) 113-118. doi:10.1039/C1CY00169H.

[19] J. Xiong, T. Kan, X. Li, T. Ye, Q. Li, Effects of Current upon Electrochemical Catalytic Reforming of Anisole, Chinese J. Chem. Phys. 23 (2010) 693-700. doi:10.1088/1674-0068/23/06/693-700.

[20] M.A. González-Borja, D.E. Resasco, Anisole and Guaiacol Hydrodeoxygenation over Monolithic Pt-Sn Catalysts, Energy \& Fuels. 25 (2011) 4155-4162. doi:10.1021/ef200728r.

[21] W. Mu, H. Ben, A. Ragauskas, Y. Deng, Lignin Pyrolysis Components and Upgrading-Technology Review, Bioenergy Res. 6 (2013) 1183-1204. doi:10.1007/s12155-013-9314-7.

[22] H. Weigold, Behaviour of Co-Mo-Al2O3 catalysts in the hydrodeoxygenation of phenols, Fuel. 61 (1982) 1021-1026. doi:10.1016/0016-2361(82)90104-1.

[23] E. Odebunmi, Catalytic hydrodeoxygenation I. Conversions of o-, p-, and mcresols, J. Catal. 80 (1983) 56-64. doi:10.1016/0021-9517(83)90229-4. 
419 [24] R. Kallury, Hydrodeoxygenation of hydroxy, methoxy and methyl phenols with molybdenum oxide/nickel oxide/alumina catalyst, J. Catal. 96 (1985) 535-543. doi:10.1016/0021-9517(85)90321-5.

422

423

424

425

426

427

428

429

430

431

432

433

434

435

436

437

438

439

440

441

442

443

[25] B.S. Gevert, J.-E. Otterstedt, F.E. Massoth, Kinetics of the HDO of methylsubstituted phenols, Appl. Catal. 31 (1987) 119-131. doi:10.1016/S01669834(00)80671-5.

[26] E. Laurent, B. Delmon, Study of the hydrodeoxygenation of carbonyl, carboxylic and guaiacyl groups over sulfided $\mathrm{CoMo} / \mathrm{Y}-\mathrm{Al} 2 \mathrm{O} 3$ and $\mathrm{NiMo} / \mathrm{Y}-\mathrm{Al} 2 \mathrm{O} 3$ catalyst, Appl. Catal. A Gen. 109 (1994) 97-115. doi:10.1016/0926-860X(94)85005-4.

[27] T. Viljava, Effect of $\mathrm{H} 2 \mathrm{~S}$ on the stability of CoMo/Al2O3 catalysts during hydrodeoxygenation, Catal. Today. 60 (2000) 83-92. doi:10.1016/S0920$5861(00) 00320-5$.

[28] M. Ferrari, R. Maggi, B. Delmon, P. Grange, Influences of the Hydrogen Sulfide Partial Pressure and of a Nitrogen Compound on the Hydrodeoxygenation Activity of a CoMo/Carbon Catalyst, J. Catal. 198 (2001) 47-55. doi:10.1006/jcat.2000.3103.

[29] Y. Romero, F. Richard, S. Brunet, Hydrodeoxygenation of 2-ethylphenol as a model compound of bio-crude over sulfided Mo-based catalysts: Promoting effect and reaction mechanism, Appl. Catal. B Environ. 98 (2010) 213-223. doi:10.1016/j.apcatb.2010.05.031.

[30] A. Smirnov, S. Khromova, O. Bulavchenko, V. Kaichev, A. Saraev, S. Reshetnikov, M. Bykova, L. Trusov, V. Yakovlev, Effect of the Ni/Cu ratio on the composition and catalytic properties of nickel-copper alloy in anisole hydrodeoxygenation, Kinet. $\quad$ Catal. $55 \quad$ (2014) 69-78. doi:10.1134/S0023158414010145. 
444 [31] S. Pichaikaran, P. Arumugam, Vapour phase hydrodeoxygenation of anisole 445 over ruthenium and nickel supported mesoporous aluminosilicate, Green Chem. 18 (2016) 2888-2899. doi:10.1039/C5GC01854D.

447 [32] R. Thilakaratne, J.-P. Tessonnier, R.C. Brown, Conversion of methoxy and hydroxyl functionalities of phenolic monomers over zeolites, Green Chem. 18 (2016) 2231-2239. doi:10.1039/C5GC02548F.

[33] B. Delley, An all-electron numerical method for solving the local density functional for polyatomic molecules, J. Chem. Phys. 92 (1990) 508-517.

[34] B. Delley, From molecules to solids with the DMol3 approach, J. Chem. Phys. 113 (2000) 7756. doi:10.1063/1.1316015.

[35] M. Elanany, M. Koyama, M. Kubo, P. Selvam, A. Miyamoto, Periodic density functional investigation of Bronsted acidity in isomorphously substituted chabazite and AIPO-34 molecular sieves, Microporous Mesoporous Mater. 71 (2004) 51-56. doi:10.1016/j.micromeso.2004.03.018.

[36] B. Kalita, R.C. Deka, DFT study of CO adsorption on neutral and charged Pdn(n 460 = 1-7) clusters, Eur. Phys. J.

D. 53 (2009) 51-58. doi:10.1140/epjd/e200900044-6.

[37] J.P. Perdew, K. Burke, M. Ernzerhof, Generalized Gradient Approximation Made 463 Simple, Phys. Rev. Lett. $77 \quad$ (1996) 3865-3868. doi:10.1103/PhysRevLett.77.3865.

[38] S. Grimme, Semiempirical GGA-type density functional constructed with a longrange dispersion correction, J. Comput. Chem. 27 (2006) 1787-1799. doi:10.1002/jcc.20495.

[39] F.L. Hirshfeld, Bonded-atom fragments for describing molecular charge densities, 
Theor. Chim. Acta. 44 (1977) 129-138. doi:10.1007/BF00549096.

470

471

472

473

474

475

476

477

478

479

480

481

482

483

484

485

486

487

488

489

490

491

492

493

[40] Y. Huang, X. Dong, M. Li, Y. Yu, J. Gao, Y. Zheng, G.B. Fitzgerald, J. de Joannis, Y. Tang, I.E. Wachs, S.G. Podkolzin, Y. Huang, X. Dong, M. Li, M. Zhang, Y. Yu, A density functional theory study on ethylene formation and conversion over P modified ZSM-5, Catal. Sci. Technol. 5 (2015) 1093-1105. doi:10.1039/C4CY01205D.

[41] Y. Huang, X. Dong, M. Li, M. Zhang, Y. Yu, Density Functional Theory study of the structural and electronic properties of H3PO4/ZSM-5, RSC Adv. 4 (2014) 14573. doi:10.1039/c3ra47551d.

[42] K. Johnston, A. Gulans, T. Verho, M.J. Puska, Adsorption structures of phenol on the $\mathrm{Si}(001)-\left(2^{*} 1\right)$ surface calculated using density functional theory, Phys. Rev. B. 81 (2010) 235428. doi:10.1103/PhysRevB.81.235428.

[43] R. Peköz, D. Donadio, Effect of van der Waals interactions on the chemisorption and physisorption of phenol and phenoxy on metal surfaces, J. Chem. Phys. 145 (2016) 104701. doi:10.1063/1.4962236.

[44] M.E. Davis, R.J. Davis, Heterogeneous Catalysis, in: Fundam. Chem. React. Eng., McGraw-Hil, New York, 2003: pp. 133-183.

[45] R.C. Runnebaum, T. Nimmanwudipong, D.E. Block, B.C. Gates, Catalytic Conversion of Anisole: Evidence of Oxygen Removal in Reactions with Hydrogen, Catal. Letters. 141 (2011) 817-820. doi:10.1007/s10562-010-0510-1.

[46] R.C. Runnebaum, R.J. Lobo-Lapidus, T. Nimmanwudipong, D.E. Block, B.C. Gates, Conversion of anisole catalyzed by platinum supported on alumina: The reaction network, Energy \& Fuels. 25 (2011) 4776-4785. doi:10.1021/ef2010699.

[47] K. Wang, X. Dong, Z. Chen, Y. He, Y. Xu, Z. Liu, Highly selective synthesis of para-cresol by conversion of anisole on ZSM-5 zeolites, Microporous 
Mesoporous Mater. 185 (2014) 61-65. doi:10.1016/j.micromeso.2013.11.007.

495

496

497

498

499

500

501

502

503

504

505

506

507

508

509

510

511

512

513

514

515

516

517

[48] X. Zhu, R.G. Mallinson, D.E. Resasco, Role of transalkylation reactions in the conversion of anisole over HZSM-5, Appl. Catal. A Gen. 379 (2010) 172-181. doi:10.1016/j.apcata.2010.03.018.

[49] C.J. Mackie, R.K. Doolan, F.P. Nelson, Kinetics of the thermal decomposition of methoxybenzene(anisole), J. Phys. Chem. C. 93 (1989) 664-670. doi:0022365418912093-0664\$01.50/0 Lin.

[50] F.L. Lambert, Substituent effects on the benzene ring: A demonstration, J. Chem. Educ. 35 (1958) 342-343.

[51] K.A. Rogers, Y. Zheng, Selective Deoxygenation of Biomass-Derived Bio-oils within Hydrogen-Modest Environments: A Review and New Insights, ChemSusChem. 9 (2016) 1750-1772. doi:10.1002/cssc.201600144.

[52] Q. Xia, Z. Chen, Y. Shao, X. Gong, H. Wang, X. Liu, S.F. Parker, X. Han, S. Yang, Y. Wang, Direct hydrodeoxygenation of raw woody biomass into liquid alkanes, Nat. Commun. 7 (2016) 11162. doi:10.1038/ncomms11162.

[53] B. Yang, R. Burch, C. Hardacre, G. Headdock, P. Hu, Understanding the Optimal Adsorption Energies for Catalyst Screening in Heterogeneous Catalysis, ACS Catal. 4 (2014) 182-186. doi:10.1021/cs400727f.

[54] S. Cui, N. Zhao, C. Shi, C. Feng, C. He, J. Li, E. Liu, Effect of Hydrogen Molecule Dissociation on Hydrogen Storage Capacity of Graphene with Metal Atom Decorated, J. Phys. Chem. C. 118 (2013) 8-13. doi:J. Phys. Chem.

[55] S. Klacar, H. Grönbeck, H2 dissociation over Ag/Al2O3: the first step in hydrogen assisted selective catalytic reduction of NOx, Catal. Sci. Technol. 3 (2013) 183-190. doi:10.1039/C2CY20343J. 
518 [56] E. Florez, T. Gomez, J.A. Rodriguez, F. Illas, On the dissociation of molecular 519 hydrogen by Au supported on transition metal carbides: choice of the most 520 active support, Phys. Chem. Chem. Phys. $13 \quad$ (2011) 6865. 521 doi:10.1039/c0cp02882g. 